\title{
Breath-hold imaging of the coronary arteries using quiescent-interval slice-selective (qiss) magnetic resonance angiography - pilot study at 1.5 tesla and 3 tesla
}

Robert R Edelman ${ }^{1,2^{*}}$, Shivraman Giri ${ }^{5}$, Amit Pursnani ${ }^{1,3}$, Marcos P Ferreira Botelho ${ }^{1}$, Wei Li ${ }^{1,4}$, loannis Koktzoglou ${ }^{1,4}$

From 19th Annual SCMR Scientific Sessions

Los Angeles, CA, USA. 27-30 January 2016

\section{Background}

Coronary magnetic resonance angiography (MRA) is usually obtained with a free-breathing navigator-gated $3 \mathrm{D}$ acquisition. Our aim was to develop an alternative breath-hold approach that would allow the coronary arteries to be evaluated in a much shorter time and without risk of degradation by respiratory motion artifacts. For this purpose, we implemented a breath-hold, non-contrast-enhanced, quiescent-interval slice-selective (QISS) 2D technique. Sequence performance was compared at 1.5 and 3 Tesla using both radial and Cartesian $\mathrm{k}$-space trajectories.

\section{Methods}

The left coronary circulation was imaged in six healthy subjects and one patient with coronary artery disease. Breath-hold QISS was compared with T2-prepared 2D balanced steady-state free-precession (bSSFP) and freebreathing, navigator-gated 3D bSSFP.

\section{Results}

Approximately $102.1-\mathrm{mm}$ thick slices were acquired in a single 20-sec breath-hold using two-shot QISS, and 20 slices using single-shot QISS. QISS contrast-to-noise ratio (CNR) was 1.5 -fold higher at 3 Tesla than at 1.5 Tesla. Cartesian QISS provided the best coronary-tomyocardium CNR, whereas radial QISS provided the sharpest coronary images. QISS image quality exceeded that of free-breathing 3D coronary MRA with few artifacts at either field strength. Compared with

\footnotetext{
${ }^{1}$ Radiology, NorthShore University HealthSystem, Evanston, IL, USA
} Full list of author information is available at the end of the article

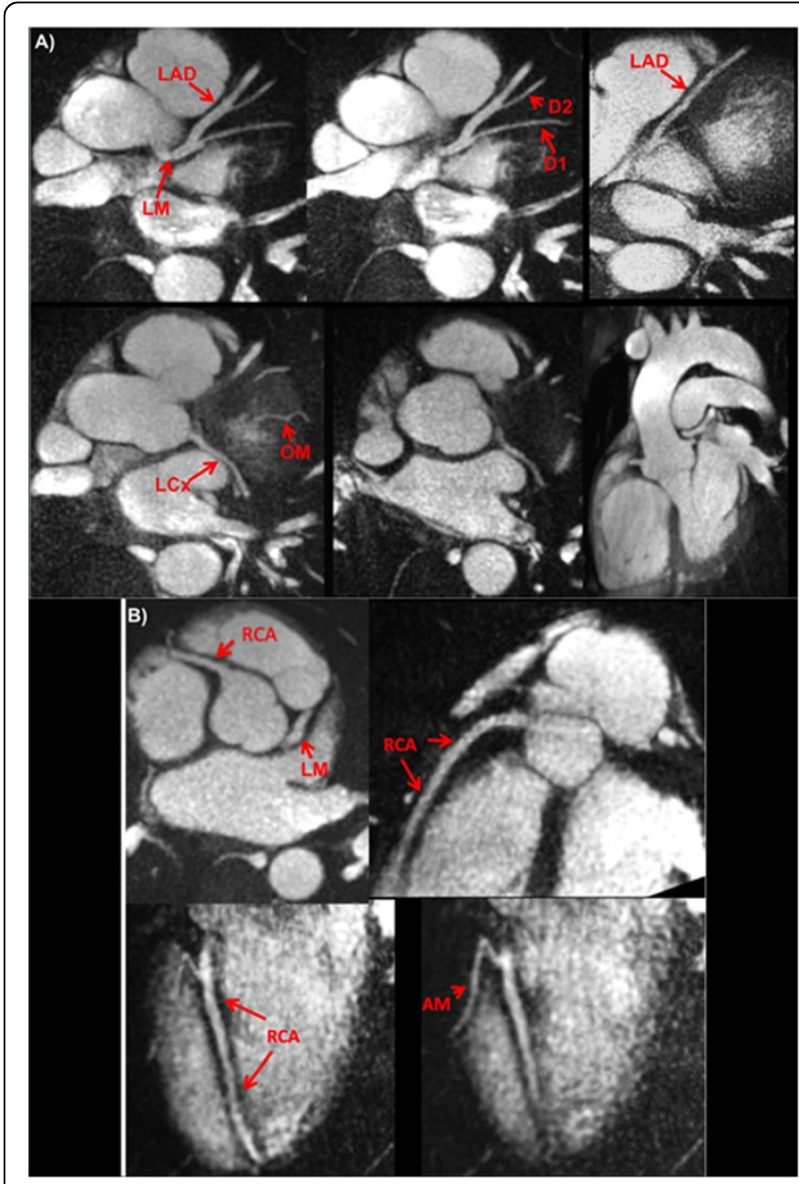

Figure 1 Examples of thin MIPs reconstructed from single breath hold radial QISS. Images were acquired at 3 Tesla using various scan orientations. A-Aorta and left coronary circulation. B-Right coronary circulation. 
T2-prepared 2D bSSFP, multi-slice capability was not restricted by the specific absorption rate at 3 Tesla and pericardial fluid signal was better suppressed. In addition to depicting the coronary arteries, QISS could image intra-cardiac structures, pericardium, and the aortic root in arbitrary slice orientations.

\section{Conclusions}

Breath-hold QISS is a simple, versatile, and time-efficient method for coronary MRA that provides excellent image quality at both 1.5 and 3 Tesla. Image quality exceeded that of free-breathing, navigator-gated 3D MRA in a much shorter scan time. QISS also allowed rapid multi-slice bright-blood, diastolic phase imaging of the heart, which may have complementary value to multi-phase cine imaging. We conclude that, with further clinical validation, QISS might provide an efficient alternative to commonly used free-breathing coronary MRA techniques.

\section{Authors' details}

${ }^{1}$ Radiology, NorthShore University HealthSystem, Evanston, IL, USA.

${ }^{2}$ Radiology, Feinberg School of Medicine, Northwestern University, Chicago,

IL, USA. ${ }^{3}$ Medicine, Pritzker School of Medicine, University of Chicago,

Chicago, IL, USA. ${ }^{4}$ Radiology, Pritzker School of Medicine, University of

Chicago, Chicago, IL, USA. ${ }^{5}$ Siemens Healthcare, Chicago, IL, USA.

Published: 27 January 2016
Submit your next manuscript to BioMed Central and take full advantage of:

- Convenient online submission

- Thorough peer review

- No space constraints or color figure charges

- Immediate publication on acceptance

- Inclusion in PubMed, CAS, Scopus and Google Scholar

- Research which is freely available for redistribution

Submit your manuscript at www.biomedcentral.com/submit 